Goldschmidt 2021 Abstract

https://doi.org/10.7185/gold2021.6144

\title{
The evolution of oxygen-utilizing enzymes suggests early biosphere oxygenation \\ JAGODA JABLONSKA
}

Weizmann Institute of Science

Presenting Author: jagoda.jablonska@weizmann.ac.il

Production of molecular oxygen was a turning point in Earth's history. The geological record indicates the Great Oxidation Event (GOE), marking a permanent transition to an oxidizing atmosphere ca 2.4 BYA. However, the degree to which oxygen was available to life prior to the atmosphere's oxygenation remains unknown. Here, phylogenetic analysis of all known oxygen-utilizing and producing enzymes $\left(\mathrm{O}_{2}\right.$-enzymes $)$ indicates that oxygen became widely available to living organisms well prior to the GOE. About $60 \%$ of the $\mathrm{O}_{2}$-enzyme families whose birth could be dated seem to have emerged at the split of terrestrial and marine bacteria (22 families, compared to 2 families assigned to the last universal common ancestor). This node, dubbed the Last Universal Oxygen Ancestor, or LUOA, coincides with a burst of emergence of oxygenases as well as other oxidoreductases thus suggesting a wider availability of oxygen ca. 3.1 BYA. 